\title{
Impacts of the Wenchuan earthquake on tree mortality and biomass carbon stock
}

\author{
Shuai Qiu • Ming Xu • Yunpu Zheng • Renqiang Li • \\ Michelle Hang Gi Wong • Liyun Zhang • Lixiang Liu • \\ Changhong Lai $\cdot$ Wen Zhang
}

Received: 3 October 2014/ Accepted: 3 February 2015/Published online: 11 February 2015

(C) Springer Science+Business Media Dordrecht 2015

\begin{abstract}
The Wenchuan earthquake caused tremendous damages to forests, which could increase tree mortality, disrupt forest carbon cycling, and pose serious challenge to sustainable forest management. In this study, we analyzed data from 871 permanent forest plots from the Sichuan forest inventory (SFI) system to quantify the impacts of 2008 Wenchuan earthquake on tree mortality and forest biomass carbon. Our results showed that the 5-year tree mortality had significantly increased from 2.26 to $3.52 \%$ in the region with seismic intensity of $\geq$ VII (VII and above), and even more dramatically in the hardest hit zone with seismic intensity of $\mathrm{X}$ and XI, which showed an increase from 3.77 to $8.96 \%$. It is estimated that the Wenchuan earthquake had killed as much as 34.5 million trees and mobilized a dead carbon pool of $1050 \mathrm{Gg} \mathrm{C}\left(7.87 \mathrm{Mg} \mathrm{C} / \mathrm{km}^{2} / \mathrm{a}\right)$ in the region with seismic intensity of $\geq$ VII. Our results suggested that the earthquake was the main cause of this
\end{abstract}

Electronic supplementary material The online version of this article (doi:10.1007/s11069-015-1653-6) contains supplementary material, which is available to authorized users.

S. Qiu · Y. Zheng · R. Li · M. H. G. Wong · L. Zhang · L. Liu

Key Laboratory of Ecosystem Network Observation and Modeling, Institute of Geographic Sciences and Natural Resources Research, University of Chinese Academy of Sciences, Beijing, China e-mail: qiushuai2019@163.com

S. Qiu · L. Zhang

University of Chinese Academy of Science, 100049 Beijing, China

M. Xu ( ()

Department of Ecology, Evolution and Natural Resources, Center for Remote Sensing and Spatial Analysis, Rutgers University, New Brunswick, NJ 08901, USA

e-mail: mingxu@crssa.rutgers.edu

Y. Zheng

School of water conservancy and hydropower, Hebei University of Engineering, 056038 Handan, China

C. Lai · W. Zhang

Department of Sichuan Provincial Forest Resources Monitoring Center, Sichuan Forestry Inventory and Planning Institute, Sichuan, China 
risen tree mortality and the loss of huge amount of forest biomass carbon. This study demonstrated that tree mortality derived from forest plots can be used to estimate disasterinduced forest carbon loss for the purpose of hazard assessment.

Keywords Tree mortality $\cdot$ Forest biomass carbon $\cdot$ Hazard $\cdot$ Seismic intensity $\cdot$ Disaster assessment $\cdot$ Natural and planted forests

\section{Introduction}

Tree mortality plays a key role in shaping forest structure and stand dynamics, and tree deaths could be resulted from biotic and abiotic factors, such as environmental, biological (e.g., competition) and physiological stresses, and anthropological disturbances (Fridman and Ståhl 2001). While logging is known to be the major driving factor for tree deaths and carbon loss in many parts of the world, catastrophic events, such as earthquake, wildfire, hurricane, snowstorm, insect outbreaks, and landslides, could also result in abrupt tree deaths (Van Mantgem et al. 2009; Peng et al. 2011; Dietze and Moorcroft 2011). Previous studies suggested that large earthquakes could cause severe and immediate damages to forests in tectonically active regions (Stewart and Veblen 1982; Allen et al. 1999). For example, Allen et al. (1999) showed that earthquake-induced damages had caused $24 \%$ tree mortality and $22.5 \%$ tree injury on Basin Creek plots in Southern Alps, New Zealand.

Large earthquakes not only destroy forests immediately through geographic impacts such as landslides and debris flows, but may also induce mortality of the remaining trees in subsequent years (Cheng et al. 2012). The immediate impacts come from abrupt energy release during an earthquake, disrupting ground surfaces, removing soils and aboveground biomass, and deposit rocks and sediments into valleys in mountainous terrain (Swiss Reinsurance Company 2000; Hilton et al. 2011). Slow death of trees following a destructive earthquake may be resulted from physical damages caused to their tree crown, roots and rhizosphere, rendering them more vulnerable to pests and diseases, and environmental stresses; such an ecosystem would take a long time to restore (Bellingham et al. 1995; Harcombe et al. 1998; West et al. 2011; Ramos-Scharrón et al. 2012). Trees that are physically damaged by seismic rock falls, tree fall or landslides may show reduction in growth and resistance to stresses, and are more likely to die within the next several years (Allen et al. 1999; Cheng et al. 2012). Thus, the damage of earthquakes on forests could be underestimated without considering the subsequent long-term impacts on tree mortality. Moreover, topographic position and substrate characteristics are also thought to be major determinants of forest damage at fine spatial scales (Kitzberger et al. 1995). And the severity of forest damage by earthquakes strongly varied with distance from epicenter (Vittoz et al. 2001), as well as forest types, tree vigor, stand biomass, and soil conditions (Pedersen 1998). In addition, natural forests usually have more complex forest structures and rich biodiversity than plantations (Knoke et al. 2005), thus the natural forests may be more resistant than the planted forests to catastrophic threats such as freezing damages and earthquakes. However, few studies were conducted to compare the resistant ability on earthquakes between the natural and planted forests.

The 2008 Wenchuan earthquake has triggered numerous and widespread landslides, debris flows, and lake water outflow, which led to tree death (Cui et al. 2009; Cheng et al. 2009). Previous studies have mostly focused on immediate tree mortality caused by 

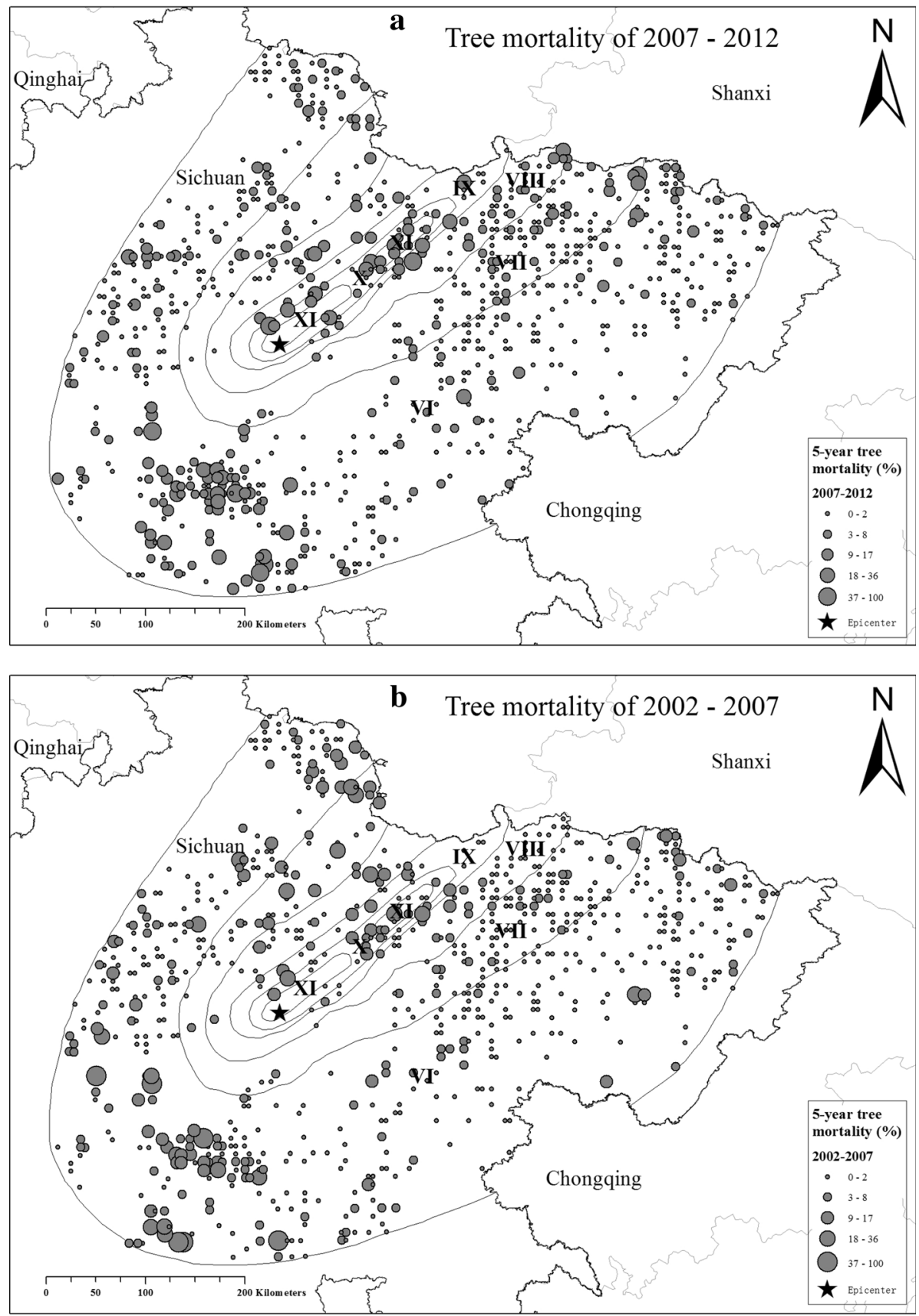

Fig. 1 Five-year tree mortality (\%) of plots during 2007-2012 and 2002-2007. Tree mortality of each plot was represented by black cycles in different sizes. VI, VII, VIII, XI, and X were the seismic intensities. After the earthquake, plots of higher tree mortality are more likely to be found at high seismic intensity regions 
earthquakes, while we believe that quantifying the long-term (non-immediate impacts) tree mortality and the loss of forest carbon pools would provide more accurate insights into the destructive effects of the Wenchuan earthquake, and help guiding policy-making for forest management in this tectonically active region. In addition, we also focus on investigating the earthquake impacts on plantations versus natural forests because plantations have been developed rapidly in southern China in the past years. For further development of forestry in this earthquake-frequent region, it has been widely concerned to develop more plantations or protect more natural forests. Moreover, we collected data from 871 permanent plots in the forest inventory system in Sichuan Province, southwestern China, to investigate the 5-year tree mortality and carbon loss before and after the Wenchuan earthquake to quantify its long-term impacts on forest ecosystems at different seismic intensities.

\section{Materials and methods}

\subsection{Data for the study area}

The Wenchuan earthquake $(M=8.0)$ struck Longmen Shan mountain range between the eastern rim of Tibetan Plateau and the western part of Sichuan Basin of China on May 12 2008 (Parsons et al. 2008; Hubbard and Shaw 2009). The study area is defined as the region with a seismic intensity (SI) of $\geq \mathrm{VI}$ (VI and above) according to the distribution map of Wenchuan earthquake intensity (Version 3.0, China Earthquake Administration, 2009). The area that experienced seismic intensity (SI) of VI-XI was 149,943; 32,783; 18,078; $7399 ; 4185$; and $2478 \mathrm{~km}^{2}$, respectively, adding up to a total of $214,867 \mathrm{~km}^{2}$ (Fig. 1). The forest coverage in the study area before the earthquake was $32.47 \%$ according to the Inventory for Forest Management, Planning and Design (2007).

We analyzed the data collected from permanent plots of the Sichuan forest inventory (SFI) system. These plots are systemically re-measured every 5 years, and the most recent inventory was conducted in 2012. Each plot has an area of $667 \mathrm{~m}^{2}$, and the plots were spaced at 4 or $8 \mathrm{~km}$. Each tree with a diameter at breast height (DBH) $>5 \mathrm{~cm}$ was tagged, measured, and recorded. We compiled and analyzed a data set of 871 forest plots that had been re-measured at least two times since 2002. These plots have an average elevation of $1723 \mathrm{~m}$ (range between 268 and $4280 \mathrm{~m}$ ), an annual average temperature of $12.9^{\circ} \mathrm{C}$, and an annual precipitation of $991 \mathrm{~mm}$ during 2002-2012. In order to identify the effects of various ecological and geographic factors, we analyzed tree mortality for different forest types (broadleaf, coniferous), origins (natural or planted), stand mean diameter (DBH $5-10,10-20,>20 \mathrm{~cm})$, elevation $(<1000,1000-2500,>2500 \mathrm{~m})$, and slope $(<24,24-32$, $>32^{\circ}$ ). Moreover, we compared plots with or without other types of natural disturbances. According to the Manual of Forest Inventory, all the catastrophic events were categorized into four types, including (1) insects and diseases [recorded when more than $10 \%$ trees were injured in plots], (2) fire, (3) climate and geological hazard [such as earthquakes, snowstorms, drought, and landslides], and (4) others.

\subsection{Five-year tree mortality}

All living trees, fallen logs, and snags in each plot were recorded; these data were used to calculate tree mortality, which is the number of dead trees divided by the total number of living and dead trees in each plot. We analyzed for significant changes in tree mortality before and after the earthquake within different seismic intensity regions (from VI to XI, 


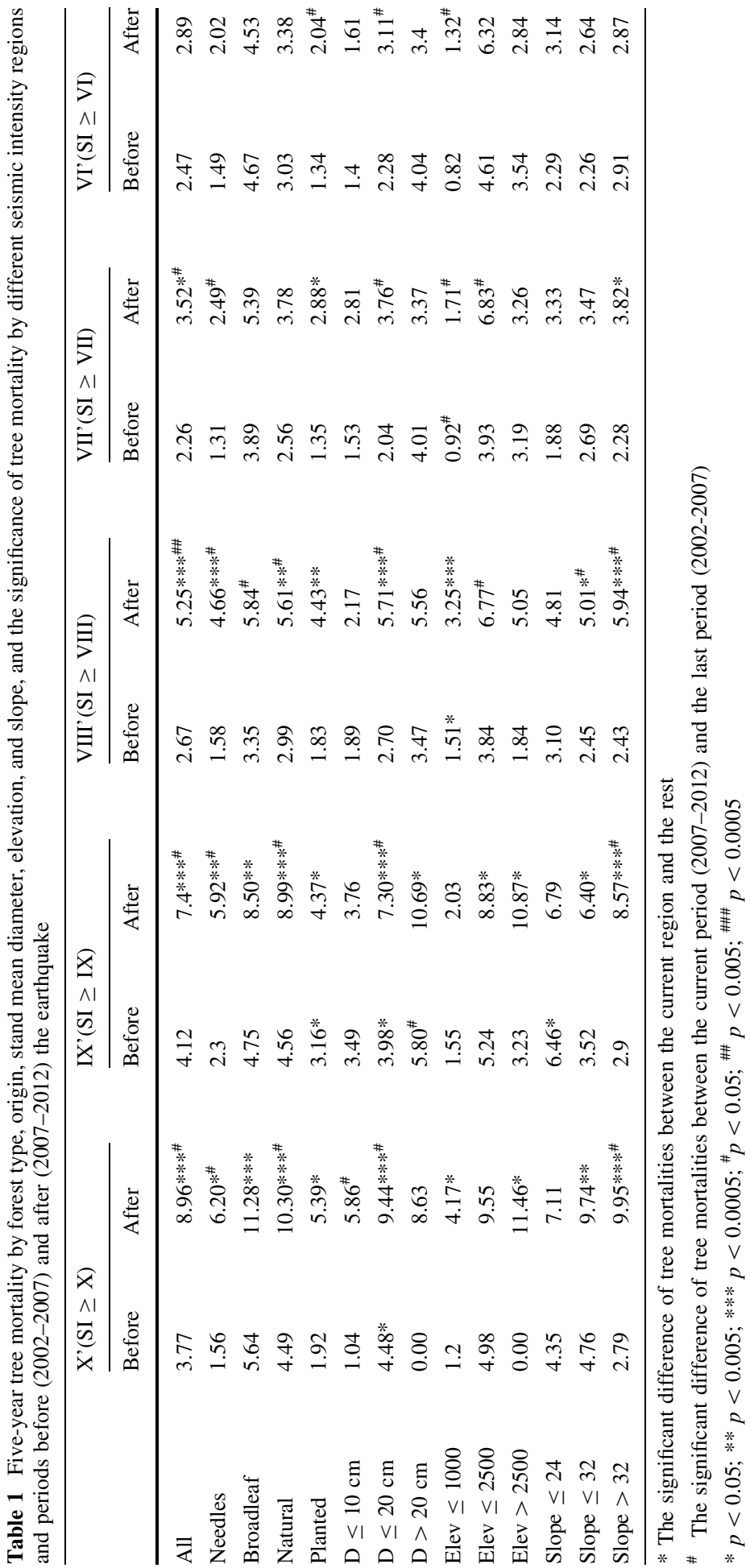


Fig. 1), and for significant differences among classes of stand as well as geographic variables using ANOVA (R, version 3.0.2). A confidence level of $P<0.05$ was applied. In the analysis, the forest status in the area with a seismic intensity of VI was used as the baseline.

\subsection{Loss of carbon stock from the earthquake}

We calculated the biomass carbon of individual tree by using the allometric equations developed for 15 tree species in the Forest Carbon Monitoring and Accounting Project by the Forestry Department of Sichuan Province (see S. Table 1, and S. Table 2). We also calculated the total carbon sink/source for the regions with seismic intensity of VI to XI. Because the biomass carbon of understory vegetation is found to be insignificant (4.7\% of total biomass carbon stock according to the Forest Carbon Monitoring and Accounting Project) in these forest ecosystems, it was excluded from the analysis. The total forest carbon stock was obtained by multiplying the average carbon density of forest biomass by the total forest area in each seismic intensity region (Brown and Lugo 1984; Brown et al. 1989), whereas afforestation and natural regeneration of forests after the earthquake were not considered in the study. Mason et al. (2013) found that the wood density in (coarse wood debris) CWD would still left 67 (39.7-99.8\%) even for trees with diameters $<30 \mathrm{~cm}$ by 19 tree species. However, most of the dead trees were removed from the sites as timber or firewood post the earthquake. Given the subtropical climate in the study area, the small amount of residuals from branches and leaves of the dead trees would decompose rapidly after the earthquake. Therefore, our objective was mainly to evaluate the carbon loss from the live wood carbon pool to the dead wood carbon pool of forests after the earthquake.

In order to quantify the dead carbon pool resulted from the earthquake, we assumed that the 5-year tree mortality before the earthquake represents a normal, stable state, while the increase in mortality rate after the earthquake represents the amount of carbon mobilized by the earthquake. Thus, we used the total forest area in year 2007, mean stand carbon density, number of trees, individual biomass carbon of dead trees, and 5year tree mortality to calculate the loss of forest carbon pools and numbers of trees, using these equations:

$$
\begin{gathered}
F_{i, \text { total }}=\overline{F_{i, \text { plot }}} \times A_{i} \\
F_{i, \text { dead }}=F_{i, \text { total }} \times M_{i, t} \\
\Delta D_{1 i}=F_{i, \text { total }} \times\left(M_{i, t}-M_{i, t-1}\right) \\
\Delta D_{2 i}=\Delta D_{1 i} \times \overline{D T}_{i}
\end{gathered}
$$

where Fi,total is the total forest carbon pool or total number of trees for region $i$; $\overline{F_{i, p l o t}}$ represents the average forest carbon density ( $\mathrm{t} / \mathrm{ha}$ ) or average total number of trees in region $i ; F_{\mathrm{i} \text {,dead }}$ is the total dead number of trees in region $i ; \Delta D_{1 \mathrm{i}}$ is the earthquake mobilized number of trees in region $i ; \Delta D_{2 \mathrm{i}}$ is the earthquake mobilized total forest carbon in region $i ; \overline{D T}_{i}$ is the average biomass carbon of dead tree in region $i ; A_{\mathrm{i}}$ is the forest area of the region $i ; M_{\mathrm{i}, \mathrm{t}}$ is the tree mortality of the seismic intensity region $i$ at the period of $t$; $i$ is the seismic intensity region (VI-XI); $t$ is the period. 


\section{Results}

\subsection{Effects of different earthquake intensity on tree mortality}

The average 5-year tree mortality increased slightly from 2.47 to $2.89 \%$ in the overall study area after the Wenchuan earthquake (Table 1), with the rate increased markedly toward the epicenter. For instance, in the hardest hit area (seismic intensity of X, XI), the post-earthquake tree mortality had increased by 2.4 times $(p<0.05$, Table 1$)$. Tree mortality significantly increased from 2.26 to $3.52 \%, 2.67$ to $5.25 \%, 4.12$ to $7.4 \%$, and 3.77 to $8.96 \%$ in the regions with a seismic intensity of $\geq$ VII (VII and above), $\geq$ VIII (VIII and above), $\geq \mathrm{IX}$ (IX and above), and $\geq \mathrm{X}$ ( $\mathrm{X}$ and above), respectively, compared with the pre-earthquake (2002-2007) levels (Table 1). The spatial pattern of tree mortality and the regions with different seismic intensity showed oval-shaped isoclines (Fig. 1). Tree mortality increased from $2.58 \%$ in the region with an intensity of grade VI to $8.80 \%$ in the region where the earthquake intensity reached grade XI. Interestingly, we found that tree mortality showed a slight increase with intensity even before the earthquake (Fig. 2), indicating tree mortality was not evenly distributed across the region. Further analyzed results showed that the earthquake had significantly increased the exponent from 0.1435 to 0.2971 in the exponential functions, resulting in much greater mortality rates at high intensity levels (Fig. 2).

\subsection{Impacts of other disturbances on tree mortality}

According to the disturbance events recorded during the period of 2002-2007 and 2007-2012, the proportion of plots with no disturbance events increased from 76.79 to

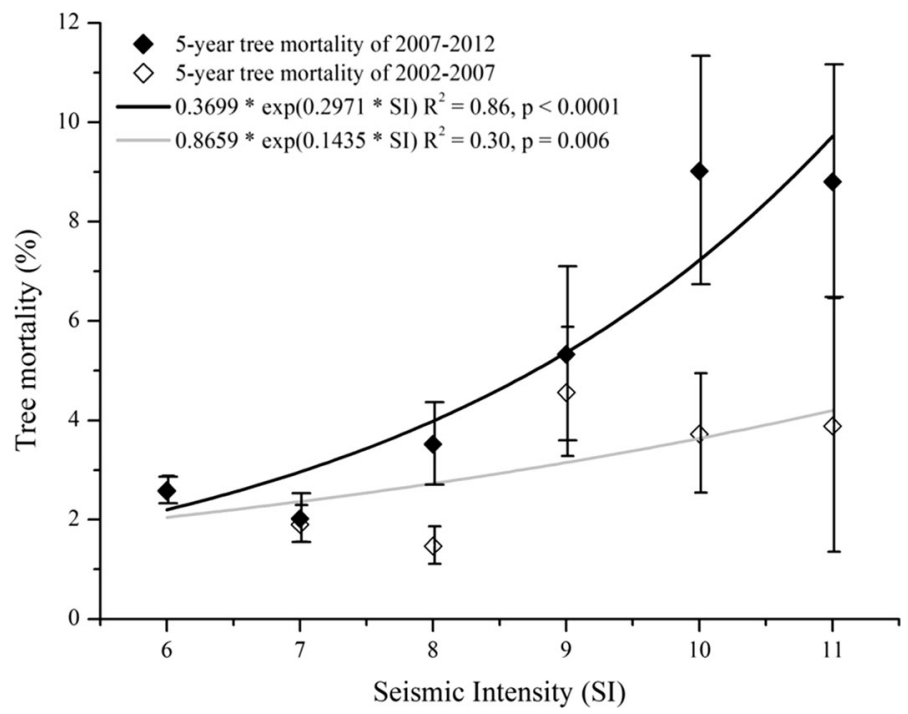

Fig. 2 Five-year tree mortality and standard errors for the regions with seismic intensity from VI to XI during the year 2002-2007 and 2007-2012. The 5-year tree mortality increased exponentially as the seismic intensity increased, and the $R^{2}$ were $0.30(p=0.006)$ and $0.86(p<0.0001)$ before and after the earthquake, respectively. The increased rate of tree mortality after the earthquake was much higher than the year 2002-2007, especially in the higher seismic intensity regions 
$87.17 \%$ since the earthquake and the corresponding tree mortality slightly decreased from 2.4 to $2.0 \%(p=0.09)$ after the earthquake in the reference region with SI of VI. The proportion of plots with insects and diseases had decreased from 18.87 to $9.27 \%$, and tree mortality had changed from 1.99 to $1.95 \%(p=0.90)$; the proportion of plots with fire, wind, snow, landslide, drought, and other hazards decreased from 4.33 to $3.55 \%$, and tree mortality had increased from 8.47 to $19.12 \%$ ( $p$ value $=0.09$ ). However, in the severe seismic impact region with SI of VII to XI, the 5-year tree mortality increased from 2.34 to $3.19 \%$ of plots with no disturbance events, from 1.58 to $4.33 \%$ of plots with insects and diseases, and decreased from 6.24 to $5.22 \%$ for wind, snow, landslide, and other hazards.

\subsection{Impacts of earthquake on tree mortality under different ecological and geographic conditions}

The 5-year tree mortality increased after the earthquake for different classes of species, forest origins, elevation, slope, and stand mean diameter (except $D>20 \mathrm{~cm}$ ) in the regions with SI of $\geq$ VII to $\geq X$ (Table 1). In this region, the tree mortality of the natural forests was higher than the planted forests; meanwhile, the tree mortality of broadleaf forests was higher than the coniferous forests before and after the earthquake. The earthquake-induced tree mortality increased from 2.56 to $3.78 \%(p=0.06)$ for the natural forests and $1.35-2.88 \%(p=0.07)$ for the planted forests. Moreover, the earthquake also increased tree mortality from 1.31 to $2.49 \%(p=0.01)$ for the coniferous forests and form 3.89 to $5.39 \%(p=0.2)$ for the broadleaf forests, respectively. In addition, the forests featured high tree mortalities at larger stand mean diameter $(>10 \mathrm{~cm}$ ), higher elevations (elevation ranged from 1000 to $2500 \mathrm{~m}$ ), and steeper slopes (slope $>32^{\circ}$ ) in the region of VII' (Table 1).

The Wenchuan earthquake significantly increased the tree mortality rates by 47.7 and $113.3 \%$ for the natural and planted forests, in the region with SI of $\geq$ VII. Natural forests in the study region are found on steeper slopes (an average of $28.8^{\circ}$ as compared with $23.5^{\circ}$ in plantations), at higher elevations (an average of $2082 \mathrm{~m}$ as compared with $796 \mathrm{~m}$ ), with larger stand mean diameter $(19.6 \mathrm{~cm}$ as compared with $12.1 \mathrm{~cm})$, and slightly higher seismic intensity (an average SI of 6.66 as compared with 6.49) than planted forests. The coniferous plots account for $59 \%$ of plots for natural forests, less than that in the planted

Table 2 Five-year tree mortality before and after the Wenchuan earthquake for natural and planted forests classified by slope, elevation, species, and stand mean diameter

\begin{tabular}{|c|c|c|c|c|c|c|c|c|c|}
\hline \multirow[t]{3}{*}{ Origin } & & \multicolumn{8}{|c|}{ 5-Year tree mortality } \\
\hline & & \multicolumn{2}{|l|}{ Slope } & \multicolumn{2}{|c|}{ Elevation } & \multicolumn{2}{|l|}{ Species } & \multicolumn{2}{|l|}{ D } \\
\hline & & $\leq 24$ & $>24$ & $\leq 1000$ & $>1000$ & Needles & Broadleaf & $\leq 12 \mathrm{~cm}$ & $>12 \mathrm{~cm}$ \\
\hline \multirow[t]{3}{*}{ Natural } & Before & 1.99 & 2.85 & 0.91 & 3.81 & 1.50 & 4.36 & 1.56 & 3.18 \\
\hline & After & 3.55 & 3.89 & $1.66^{\#}$ & 5.38 & 2.06 & 6.25 & $3.12^{\#}$ & 4.01 \\
\hline & IR $(\%)$ & 78.6 & 36.4 & 82.7 & 41.2 & 37.8 & 43.2 & 99.8 & 26.1 \\
\hline \multirow[t]{3}{*}{ Planted } & Before & 1.69 & 0.94 & 0.94 & 2.44 & 0.89 & 1.27 & 1.23 & 1.58 \\
\hline & After & 3.02 & $2.70^{\#}$ & $1.79^{\#}$ & $5.42^{\#}$ & $3.27^{\#}$ & 1.64 & $2.62^{\#}$ & $3.19^{\#}$ \\
\hline & $\operatorname{IR}(\%)$ & 79.1 & 188.6 & 91.2 & 122.6 & 268.3 & 28.7 & 113.6 & 101.4 \\
\hline
\end{tabular}

\# The significant difference of tree mortality between the current period (2007-2012) and the last period (2002-2007)

$I R$ the increasing rate of tree mortality $(\%)$ 
forests $(75 \%)$. It must be noted that even though the earthquake increased tree mortality of the coniferous species by $268.3 \%$ (from 0.89 to $3.27 \%$ ) in planted forests, much higher than that in natural forests $(37.8 \%$, from 1.50 to $2.06 \%$ ), the increase rate of tree mortality of broadleaf species in planted forest $(28.7 \%)$ was lower than that of natural forests $(43.2 \%)$. In addition, the increases in tree mortality after the earthquake for planted forests was higher than that of the natural forests at slope $\leq 24$, slope $>24$, elevation $\leq 1000$, elevation $>1000, D \leq 12$, and $D>12$, respectively (Table 2 ).

\subsection{Effects of earthquake on biomass carbon stocks}

The Wenchuan earthquake exacerbated tree mortality and thus reduced the forest biomass carbon stocks. Our results showed that the earthquake had killed 34.5 million trees, resulted in dead carbon of $1050.11 \mathrm{Gg} \mathrm{C}$ with a flux of $7.87 \mathrm{Mg} \mathrm{C} / \mathrm{km}^{2} / \mathrm{a}$ in the region with SI of $\geq$ VII (Table 3). The earthquake had killed 1.39, 14.45, 2.20, 9.93, and 6.52 million trees, in the regions with seismic intensity of VII-XI, respectively, and the corresponding mobilized dead carbon stocks were 87.69, 439.91, 61.18, 321.46, and $139.87 \mathrm{Gg} \mathrm{C}$, respectively. Moreover, the total of 5-year forest carbon sink was 10,109.07 Gg C with a flux of $72.29 \mathrm{Mg} / \mathrm{C} / \mathrm{km}^{2} / \mathrm{a}$ in the region with the seismic intensity of $\geq$ VII according to the "Forest Carbon Monitoring and Accounting Project". That means the Wenchuan earthquake had wasted $10.4 \%$ (equals to dead carbon pool of $1050.11 \mathrm{Gg} \mathrm{C}$ divided by total carbon sink of $10,109.07 \mathrm{Gg} \mathrm{C}$ ) of the total carbon sink stability of forests in this region without considering the retention period of dead wood.

\section{Discussion}

\subsection{The Wenchuan earthquake increased tree mortality}

On the eastern side of the Tibetan plateau, the 2008 Wenchuan earthquake ruptured a large thrust fault along Longmen Shan mountain range with thousands of fatalities and widespread damages (Hubbard and Shaw 2009). Moreover, the main shock and aftershocks had directly changed the landscape, destroyed forests, and tree habitats, and led to environmental pollutions, which might have an immediate or long-term influence on tree mortality (Merrens and Peart 1992; Allen et al. 1999; Liu and Sheu 2007). For example, Allen et al. (1999) found that earthquake-induced landslides disturbed $35 \%$ of the ground surface area with an average tree mortality of $24 \%$ on Basin Creek plot in Southern Alps, New Zealand. Besides landslides, Vittoz et al. (2001a) reported that most of the trees died from the effects of shaking during the 1929 earthquake in New Zealand. In the current study, the 5 -year tree mortality after the earthquake was found to be 2.4 times of the tree mortality during the period of 2002-2007 in the hardest hit zone, including those caused by shaking, seismic-induced landslides, and long-term effects. Previous studies have also found that the severity of forest damage strongly related to the distance from earthquake's epicenter (Vittoz et al. 2001b). Similarly, our results also showed that tree mortality significantly increased as the seismic intensity increased (Fig. 2), suggesting that the geological and ecological impacts of the earthquake became more severe toward the center of impact. In addition, plots with higher tree mortality (larger than $17 \%$ ) after the earthquake was mainly located around the boundary between Tibetan plateau and Sichuan Basin at the Longmen Shan fault region (Fig. 1). Interestingly, we also found that the spatial distribution of tree mortality rates appears to be governed by earthquake intensity. It should be 


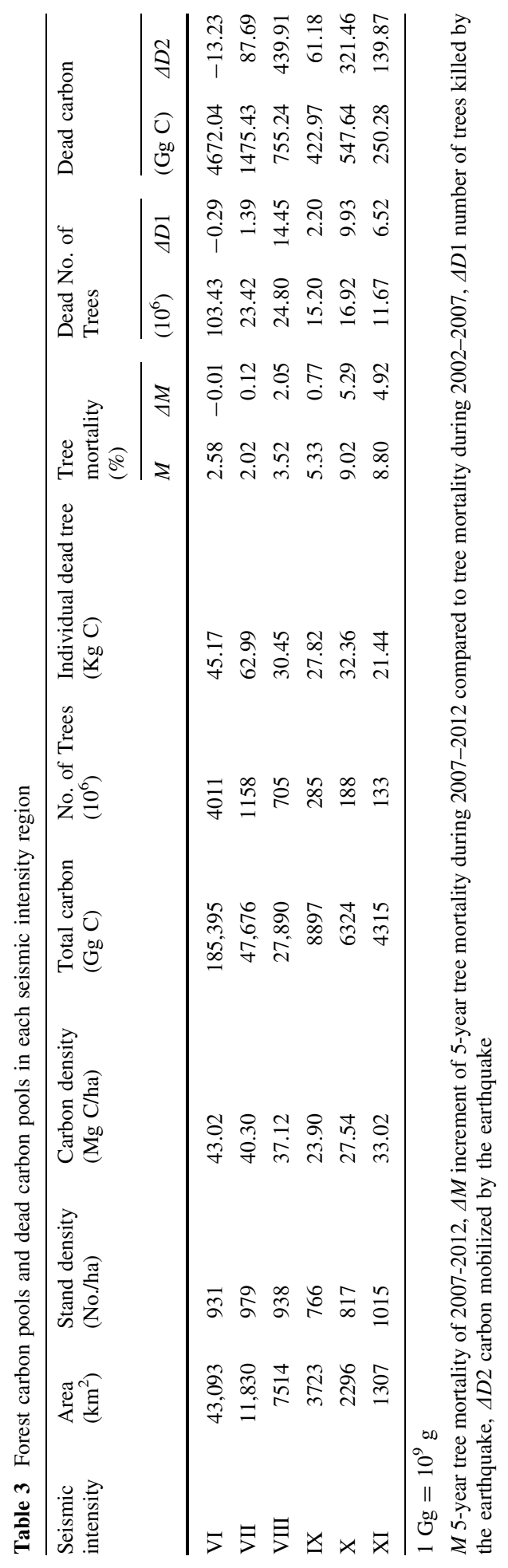


noted that tree mortality of the 85 plots (with an average rate of $7.35 \%$ ) located at the southwest region was obviously larger than other plots in the region with seismic intensity of VI (Fig. 1). However, tree mortality in these plots was $7.12 \%$ before the earthquake, which was not significant compared to the rate after the earthquake $(p=0.15)$.

Forest insect, epidemics may have severe impacts on ecosystem dynamics by causing tree mortality and reducing the growth of millions of trees across extensive areas (Kurz et al. 2008). Injured trees from an earthquake may become more sensitive to insect attack and more prone to diseases, increasing the risk of epidemics (Filip et al. 2007; Allen et al. 2010). In this study, we found that tree mortality had significantly increased in the plots with insects and disease disturbance in the region with the seismic intensity of $\geq$ VII, which might be induced by the damages from the earthquake. Meanwhile, we also found that tree mortality of plots with other disturbance was almost the same at the baseline region with SI of VI (Fig. 2), but decreased in the region with SI of $\geq$ VII, suggesting that the other disturbances were not the causations for the rising of tree mortality. In order to differentiate the impacts of earthquake, we compared tree mortality in the earlier two periods (2002-2007 vs. 1997-2002) and found that tree mortality was not statistically different $(p>0.12)$ between the two periods (data not shown). These results suggest that the damages caused by the Wenchuan earthquake were the major driving factor for the increased tree mortality during the years of 2007-2012.

\subsection{Natural forests are more resistant than plantations}

Based on the thinning response hypothesis, forest thinning is a major method for encouraging forest productivity in plantations (Skovsgaard and Vanclay 2008). Thinning increases resource and space availability to trees, allowing them to grow more efficiently and reduce mortality (Skovsgaard and Vanclay 2008). In the study region, we found that the planted forests had lower tree mortality than the natural forests after the earthquake, but when compared with their mortality rates before the earthquake, natural forests showed less degree of earthquake impacts (Table 2). The increased tree mortality rate for planted forests was higher than that of natural forests across the classified slope, elevation, and stand mean diameter, suggesting that the larger increase in mortality rate for planted forests was not driven by these factors. Moreover, the dominant coniferous species in natural forests were mainly fir and spruce; these trees have a primary taproot which provided them great resistance to sudden changes in upper soil horizons (Mauer and Palátová 2012). Whereas the dominant needle-leaf species in planted forests was Masson pine (pinus massoniana Lamb.) a light-demanding and fast-growing pioneer species, which is known to be less resistance to soil disturbance (Toledo et al. 2011). Other studies showed that natural forests usually have more complex forest structures and rich biodiversity than plantations, thus the natural forests may be more resistant to threats, such as storms, snow, fungi, and insect infestation (Knoke et al. 2005). Our results showed that the natural forests were more resistant to the earthquake than the planted forests, may be partly due to that the planted forests are at the beginning stage of succession with a more simple forest structure and species composition than the natural forests.

\subsection{The Wenchuan earthquake caused the loss of forest biomass carbon}

Earthquake could directly trigger landslides, debris flows, and other geohazards, and thus causing severe damages to forests (Meunier et al. 2007). For example, Zhang et al. (2010) estimated that the Wenchuan earthquake resulted in approximately $145 \mathrm{~km}^{2}$ of landslides 
in forest areas out of a total area of $30,000 \mathrm{~km}^{2}$ hit by the earthquake along Longmen Shan Fault Zone. Meunier et al. (2007) suggested that large earthquakes may result in 3.7-10\% area of landslides in hilly areas near epicenters. Previous studies also found that the seismogenic geohazards density of the Wenchuan earthquake had reached $3.5 / \mathrm{km}^{2}$ within $10 \mathrm{~km}$ away from the fault (Huang and Li 2009), and the forest area in the regions of IXXI had decreased by $744 \mathrm{~km}^{2}$ (Ouyang et al. 2008). It has been noted that seismic-induced damages to forests may cause the loss of large amounts of biomass carbon and have a lasting impact on forest carbon stock (Meunier et al. 2007; Hilton et al. 2011). For example, Hilton et al. (2011) found that earthquake mobilization of forest carbon in the western of Southern Alps may equate to $5-9 \mathrm{Mg} \mathrm{C} / \mathrm{km}^{2} / \mathrm{a}$ in a long-term estimates. Pan et al. (2011) and Guo et al. (2013) reported that the total carbon sink of forests ranged between 66 and $122 \mathrm{Mg} \mathrm{C} / \mathrm{km}^{2}$ per year in the south of China. In order to calculate earthquake-induced forest loss in this study, we differentiated dead trees from afforested and natural regenerated trees based on forest inventory data. Our results showed that the total carbon sink in the study area was $72.3 \mathrm{Mg} \mathrm{C} / \mathrm{km}^{2}$ per year, which was consistent with the general description for the south of China (Pan et al. 2011; Guo et al. 2013). Moreover, we also assessed the loss of forest biomass carbon based on the total carbon sink in the study area and found that the Wenchuan earthquake had caused $6.5-11.9 \%$ of forest carbon loss, especially in the hardest hit zone $\left(25.6 \mathrm{Mg} \mathrm{C} / \mathrm{km}^{2} / \mathrm{a}\right)$, the earthquake mobilized $21-38.8 \%$ of the total carbon sink of forests. Therefore, our results suggested that earthquakes could severely impact forest carbon sequestration and forest dynamics by removing trees over an extended period.

Both biotic and abiotic catastrophic events could cause severe impacts on ecosystem dynamics by reducing the growth of trees or even causing mortality over a vast area, and thus play a key role in long-term (>100 yr) loss of forest biomass carbon (Hilton et al. 2011). The damages caused by earthquakes are similar to those caused by other disasters such as hurricanes or cyclone, which could mobilize significant amounts of forest carbon pools. For example, Hurricane Mitch led to a loss of $258 \mathrm{Gg} \mathrm{C}$, for an equivalent carbon flux of $4.8-20 \mathrm{Mg} \mathrm{C} / \mathrm{km}^{2} / \mathrm{a}$ of vegetation carbon (Ramos-Scharrón et al. 2012). More severe damages of landslides triggered by cyclone Morakot in Taiwan mobilized an aboveground biomass of $1252 \mathrm{Gg} \mathrm{C}$ (West et al. 2011). In another case, the mountain pine beetle outbreak in British Columbia, Canada, had resulted in widespread tree mortality, converted the forest from a small net carbon sink to a large net carbon source and produced a cumulative loss of $36 \mathrm{Mg} \mathrm{C} / \mathrm{km}^{2} / \mathrm{a}$ of carbon (Kurz et al. 2008). Our results supported the claim that earthquake-induced damages to forest would have a long-term impact on the geographic characteristics, physical properties of soil and root architecture of trees (Cheng et al. 2012).

\section{Conclusion}

The Wenchuan earthquake was the main cause of the elevated rates of tree mortality from 2007 to 2012. As a result, tree mortality increased significantly from 2.26 to $3.52 \%$ after the earthquake compared to the last 5 years in the region with SI of $\geq$ VII, and the rate of increase rose exponentially as seismic intensity increased. Moreover, natural forests might be more resistant to disturbance than plantations, even though seismic-induced damages also varied with different forest types, stand mean diameter, elevation, and slope, especially in the severe damaged region with SI of $\geq$ VIII. The Wenchuan earthquake significantly impacted tree mortality and carbon dynamics of forests across the region. 
Overall, the earthquake had caused the death of 34.5 million trees and a loss of carbon pool of $1050.11 \mathrm{Gg} \mathrm{C}\left(7.87 \mathrm{Mg} \mathrm{C} / \mathrm{km}^{2} / \mathrm{a}\right)$.

In this study, we used tree mortality to estimate forest carbon loss resulted from a disaster, an approach that may be used to estimate the impacts of other types of hazards. Furthermore, it demonstrated the use of data collected from permanent plots in evaluating the long-term seismic-induced impacts on forests as it accurately identified the dead, survival, and regenerated individuals after the earthquake. The 8.0 earthquake provided a great opportunity to understand forest ecosystem dynamics and resistance to disturbances; further analysis on the data collected in 2017 from the same permanent plots would potentially be useful in understanding forest recovery from natural disasters.

Acknowledgments We thank Dr. Arshad Ali Shedayi for polishing the draft of the manuscript. This study was funded by the Project on Promoting New Rural Construction with Science and Technology in Qinghai Province (2013-N-556), the Forestry Department of Sichuan Province (Forest Carbon Monitoring and Accounting Project, 2009-204), and the Nature Conservancy. This research was also partially supported by the Natural Science Foundation of China (31400418) and the China Postdoctoral Science Foundation (2014M561044).

\section{References}

Allen RB, Bellingham PJ, Wiser SK (1999) Immediate damage by an earthquake to a temperate montane forest. Ecology 80:708-714

Allen CD, Macalady AK, Chenchouni H, Bachelet D, McDowell N, Vennetier M, Kitzberger T, Rigling A, Breshears DD, Hogg EH, Gonzalez P, Fensham R, Zhang Z, Castro J, Demidova N, Lim JH, Allard G, Running SW, Semerci A, Cobb N (2010) A global overview of drought and heat-induced tree mortality reveals emerging climate change risks for forest. For Ecol Manag 259:660-684

Bellingham PJ, Tanner EVJ, Healey JR (1995) Damage and responsiveness of Jamaican montane tree species after disturbance by a hurricane. Ecology 76:2562-2580

Brown S, Lugo AE (1984) Biomass of tropical forest: a new estimate based on forest volumes. Science 223:1290-1293

Brown S, Gillespie AJR, Lugo AE (1989) Biomass estimation methods for tropical forests with applications to forest inventory data. For Sci 35(4):881-902

Cheng S, Kong JM, Song HT (2009) Wenchuan 512 earthquake and giant panda habitat in Wolong, China: a review of strong earthquake effects. Front For China 4(4):388-393

Cheng S, Yang G, Yu H, Li J, Zhang L (2012) Impacts of Wenchuan Earthquake-induced landslides on soil physical properties and tree growth. Ecol Ind 15:263-270

Cui P, Zhu YY, Han YS, Chen XQ, Zhuang JQ (2009) The 12 May Wenchuan earthquake-induced landslide lakes: distribution and preliminary risk evaluation. Landslides 6:209-223

Dietze MC, Moorcroft PR (2011) Tree mortality in the eastern and central United States: patterns and drivers. Glob Chang Biol 17:3312-3326

Filip GM, Schmitt CL, Scott DW, Fitzgerald SA (2007) Understanding and defining mortality in western conifer forests. West J Appl For 22(2):105-115

Fridman J, Ståhl G (2001) A three-step approach for modelling tree mortality in Swedish forests. Scand J For Res 16:455-466

Guo ZD, Hu HF, Li P, Li NY, Fang JY (2013) Spatio-temporal changes in biomass carbon sinks in China's forests during 1977-2008. Sci China Life Sci 56(7):661-671

Harcombe P, Allen RB, Wardle JA, Platt KH (1998) Spatial and temporal patterns in stand structure, biomass, growth, and mortality in a monospecific Nothofagus solandri var. cliffortioides (Hook, f.) poole forest in New Zealand. J Sustain For 6:313-345

Hilton RG, Meunier P, Hovius N, Bellingham PJ, Galy A (2011) Landslide impact on organic carbon cycling in a temperate montane forest. Earth Surf Process Landf 36(12):1670-1679

Huang RQ, Li WL (2009) Development and distribution of geohazards triggered by the 5.12 Wenchuan Earthquake in China. Sci China Ser E: Technol Sci 52(4):810-819

Hubbard J, Shaw JH (2009) Uplift of the Longmen Shan and Tibetan plateau, and the 2008 Wenchuan ( $M=7.9)$ earthquake. Nature 458:194-197 
Kitzberger T, Veblen TT, Villalba R (1995) Tectonic influences on tree growth in northern Patagonia, Argen-tina: the roles of substrate stability and climatic variation. Can J For Res 25:1684-1696

Knoke T, Stimm B, Ammer C, Moog M (2005) Mixed forests reconsidered: a forest economics contribution on an ecological concept. For Ecol Manag 213S:102-116

Kurz WA, Dymond CC, Stinson G, Rampley GJ, Neilson ET, Carroll AL, Ebata T, Safranyik L (2008) Mountain pine beetle and forest carbon feedback to climate change. Nature 452:987-990

Liu CP, Sheu BH (2007) Effects of the 921 earthquake on the water quality in the upper stream at the Guandaushi experimental forest. Water Air Soil Poll 179:19-27

Mason NWH, Bellingham PJ, Carswell FE, Peltzer DA, Holdaway RJ, Allen RB (2013) Wood decay resistance moderates the effects of tree mortality on carbon storage in the indigenous forests of New Zealand. For Ecol Manag 305:177-188

Mauer O, Palátová E (2012) Root system development in Douglas fir (Pseudotsuga menziesii [Mirb.] Franco) on fertile sites. J For Sci 58(9):400-409

Merrens EJ, Peart DR (1992) Effects of hurricane damage on individual growth and stand structure in a hard-wood forest in New Hampshire, USA. J Ecol 80:787-795

Meunier P, Hovius N, Haines AJ (2007) Regional patterns of earthquake-triggered landslides and their relation to ground motion. Geophys Res Lett 34:L20408. doi:10.1029/2007GL031337

Ouyang ZY, Xu WH, Wang XZ, Wang WJ, Dong RC, Zheng H, Li DH, Li ZQ, Zhang HF, Zhuang CW (2008) Impact assessment of Wenchuan Earthquake on ecosystems (In Chinese). Acta Ecol Sin 28(12):5801-5809

Pan Y, Birdsey RA, Fang JY, Houghton R, Kauppi PE, Kurz WA, Phillips OL, Shvidenko A, Lewis SL, Canadell JG, Ciais P, Jackson RB, Pacala SW, McGuire AD, Piao SL, Rautiainen A, Sitch S, Hayes D (2011) A large and persistent carbon sink in the world's forests. Science 333:988-993

Parsons T, Ji C, Kirby E (2008) Stress changes from the 2008 Wenchuan earthquake and increased hazard in the Sichuan basin. Nature 454:509-510

Pedersen BS (1998) The role of stress in the mortality of mid western oaks as indicated by growth prior to death. Ecology 79:79-93

Peng CH, Ma ZH, Lei XD, Zhu Q, Chen H, Wang WF, Liu SR, Li WZ, Fang XQ, Zhou XL (2011) A drought-induced pervasive increase in tree mortality across Canada's boreal forests. Nat Clim Chang $1: 467-471$

Ramos-Scharrón GER, Castellanos EJ, Restrepo C (2012) The transfer of modern organic carbon by landslide activity in tropical montane ecosystems. J Geophys Res 117:G03016. doi:10.1029/ 2011JG001838

Skovsgaard JP, Vanclay JK (2008) Forest site productivity: a review of the evolution of dendrometric concepts for even-aged stands. Forestry 81(1):13-31

Stewart GH, Veblen TT (1982) Regeneration patterns in southern rata (Metrosiderosumbellata)-kamahi (Wein-manniaracemosa) forest in central Westland, New Zealand. NZ J Bot 20:55-72

Swiss Reinsurance Company (2000) Natural catastrophes and man-made disasters in 1999, economic research and consulting. Zurich, Sigma No. 2/2000, 35 p

Toledo JJD, Magnusson WE, Castilho CV, Nascimento HEM (2011) How much variation in tree mortality is predicted by soil and topography in Central Amazonia? For Ecol Manag 262:331-338

Van Mantgem PJ, Stephenson NL, Byrne JC, Daniels LD, Franklin JF, Fulé PZ, Harmon ME, Larson AJ, Smith JM, Taylor AH, Veblen TT (2009) Widespread increase of tree mortality rates in the western United States. Science 323(5913):521-524

Vittoz P, Stewart GH, Duncan RP (2001) Earthquake impacts in old-growth Nothofagus forests in New Zealand. J Veg Sci 12(3):417-426

West AJ, Lin CW, Lin TC, Hilton RG, Liu SH, Chang CT, Lin KC, Galy A, Sparkes RB, Hovius N (2011) Mobilization and transport of coarse woody debris to the oceans triggered by an extreme tropical storm. Limnol Oceanogr 56:77-85

Zhang WJ, Lin JY, Peng JA, Lu QF (2010) Estimating Wenchuan Earthquake induced landslides based on remote sensing. Int J Remote Sens 31(13):3495-3508 